\title{
The Diet of the Eastern Screech-Owl, Megascops asio, at the Northern Periphery of its Range
}

\author{
CHRISTIAN ARTUSO
}

Birds Studies Canada Manitoba Program. Box 24-200 Saulteaux Cr, Winnipeg, Manitoba R3J 3W3; e-mail: cartuso@birds canada.org

Artuso, Christian. 2010. The diet of the Eastern Screech-Owl, Megascops asio, at the northern periphery of its range. Canadian Field-Naturalist 124(2): 122-133.

Four techniques: pellet analysis, post-fledging nest inspection, video monitoring, and direct observation were used to study the diet of Eastern Screech-Owl (Megascops asio) in Winnipeg, Manitoba, at the northern limit of the species' range. In 2004 - 2007, 2323 prey items were analyzed. Invertebrates comprised $67 \%$ of prey captures but only $11 \%$ of biomass consumed. Seasonal shifts in diet between biologically significant periods were significant such that multiple discriminant analyses correctly classified $60 \%$ of pre-breeding season, $91 \%$ of incubation, $67 \%$ of brooding, $86 \%$ post-fledging and $100 \%$ of winter consumption. Rural pairs consumed a higher percentage of invertebrates and fewer vertebrates than suburban pairs. Prey diversity and niche breadth peaked in low-density suburban areas but rural areas and high-density suburbs were similar in terms of niche breadth. Only 37 vertebrate prey species were recorded and the total niche breadth was 6.5 , reflective of a higher degree of diet specialization than more southerly populations.

Key Words: Eastern Screech-Owl, Megascops asio, raptors, owls, diet, urban ecology, range-peripheral, Manitoba.

The diet of the Eastern Screech-Owl (Megascops asio) is comparatively well-studied; however, most studies have utilized only one or two methods such as pellet analysis, identification of prey remains in nest boxes, and stomach contents. These different methods lead to different conclusions about the relative importance of invertebrate versus vertebrate prey (Ritchison and Cavanagh 1992). Of the 11 studies included in Ritchison and Cavanagh's (1992) review, only three examined stomach contents and only one (Allen 1924) contained an observational component. Pellet samples of Eastern Screech-Owl have typically under-reported invertebrates (Errington 1932; Craighead and Craighead 1956) and have shown the percentage of mammals consumed to be very high (Cahn and Kemp 1930; Wilson 1938; Craighead and Craighead 1956; Korschgen and Stuart 1972). Studies of nest box contents also under-reported invertebrates (VanCamp and Henny 1975) and suggested a higher proportion of birds (Stewart 1969, Duly 1979) in the diet. Examination of stomach contents found high predation on invertebrates such as arthropods, especially in the summer months (Fisher 1893; Hanebrink et al 1979; Brown 1989). Duly (1979) found stomach contents contained 93\% invertebrates but cached prey only $8 \%$ invertebrates. Furthermore, most if not all of these studies under-reported soft-bodied invertebrates such as earthworms which leave no remains in pellets and which are rarely cached (Ritchison and Cavanagh 1992; Artuso 2009). This study aims to give a more comprehensive portrait of the diet of a northern population of Eastern Screech-Owl by using a combination of two observational techniques (direct observation and video record- ings) and two non-observational techniques (pellet analysis and nest-box inspection).

In the Winnipeg area, Eastern Screech-Owls reside along the rural - urban gradient and reach their highest densities in suburbs (Artuso 2009). Urbanization can greatly influence the diet of birds, sometimes offering either increased or more varied resources (Botelho and Arrowood 1996; Diermen 1996) and sometimes causing profound changes in dietary regimes (Wolf and del Rio 2000; Faeth et al. 2005). Such resources may be accompanied by increased risks such as pollution, toxins or diseases (Kostelecka-Myrcha et al. 1997; Jensen et al. 2002) and may even result in ecological traps or population sinks (Remes 2000, Battin 2004). I therefore compared the diet of screech-owls in rural, low-density suburban, and high-density suburban areas.

\section{Methods}

The study area was a circle with a radius of $40 \mathrm{~km}$ from the center of Winnipeg, Manitoba, at the northern periphery of the range of Eastern Screech-Owl. This area permitted comparisons across the human density gradient. In this area, $88 \%$ of screech-owl nests were found in riparian areas (Artuso 2009). I used four methods to identify prey: field observations, occasionally with the aid of flash photography; video footage from inside a single nest box over two nesting seasons; analysis of pellets; and the inspection of nest boxes after all young had fledged. The sample from the nest with a video camera was supplemented with observational and pellet data. I cross-referenced all prey items so that items observed in the field or video were not double counted in pellets or nest box remains. I also 
compared percentages of avian, mammalian and invertebrate prey from the video recordings with those of nearby nests with observational data only to ensure that no biases arose from this single sample. If a prey item was observed being eaten and its remains were later recovered in a pellet or nest box it was treated as observed.

Mammal and bird remains were identified by consulting the collection at the Manitoba Museum and suitable reference material (Banfield 1974; Elbroch and Marks 2001; Kays and Wilson 2002; U.S. National Fish and Wildlife Forensics Laboratory, n.d., Wageningen University Experimental Zoology Group, no date). Invertebrates were identified to family or genus level by examining head capsules, elytra and legs. The number of beetles consumed was calculated from head capsules. Feather remains in nest boxes were always assumed to represent only one individual of each species identified unless the total number of remiges or rectrices exceeded the number found on one bird. Single feathers of Wood Duck (Aix sponsa), Northern Flicker (Colaptes auratus) and European Starling (Sturnus vulgaris) without other remains found in nest boxes were not assumed to be prey as these may have been shed by these birds when visiting the boxes. The mass of each bird species was taken from Sibley (2000), and of mammals as the average of the two values (range) given by Kays and Wilson (2002). The average weight of invertebrate species was calculated from weighing individuals found in the study area. When prey was identified to genus, family, or group only, the average weight of all known members of that group in the sample was calculated and assigned to unidentified items.

Each screech-owl territory was classified as belonging to one of three categories pertaining to human density, measured in persons per hectare ( $\mathrm{p} / \mathrm{ha})$ : highdensity suburban (>30 p/ha), low-density suburban $(>10-30 \mathrm{p} / \mathrm{ha})$, and rural areas $(<10 \mathrm{p} / \mathrm{ha})$ (Artuso 2009). These categories refer to human population density rather than habitat or (altered) landscape features per se. As the study area was within one city and surrounding area, habitat was similar throughout. Nonetheless, sites where nests were found within the rural category, as operatively defined here, did have some differences from suburban areas. In particular, the number of trees and canopy cover decreased along the rural - urban gradient at screech-owl nest sites and unused sites, as did shrub density measured directly beneath cavity trees (Artuso 2009). Conversely, the number of coniferous trees (planted by humans) and the number of buildings and amount of impervious surface increased along this gradient (Artuso 2009). Rural sites had more natural cavities whereas suburban sites had more nest boxes. Rural sites also had a slightly different tree composition, such as more trembling aspen, and a denser middle story with a greater percentage of trees in the $5-10 \mathrm{~m}$ height range (as opposed to $>10 \mathrm{~m}$ ) than suburban sites. High-density suburban areas often had some high-rise buildings, including condominiums and apartment buildings, but also retained areas of riparian woodland along a river or in smaller parks.

The two broad periods of breeding and non-breeding roughly followed Ritchison and Cavanagh (1992) with an adjustment for the northern location of this study such that the breeding season was treated roughly as April through September or, where known, calculated for individual pairs as the period extending from the onset of incubation until 10 weeks after the fledging date of the oldest chick, which corresponds to typical natal dispersal (Gehlbach 1995). The nonbreeding season was thus October through March. Prey consumption was calculated by significant biological period for individual pairs based on back calculation from fledging dates. The typical dates for these periods were: pre-egg laying (1 Mar - 31 Mar), incubating (1 April - 8 May), brooding (9 May - 3 July), postfledging (4 July - 30 Sept) (Artuso 2009). The "summer" period refers to items collected from nest boxes post-fledging for which the exact time of capture is not known.

I calculated the percentage consumption of mammals, birds, amphibians plus fish, and invertebrates per nest/year. I subdivided bird species consumed into resident and locally breeding species versus winter visitors and passage migrants; mammals into rodents and nonrodents; and invertebrates into hard-bodied (detectable in pellets) versus soft-bodied (only recorded from observations). Niche breadth and overlap were calculated following Gehlbach (1994) for the four prey classes to aid comparison with three other studies (VanCamp and Henny 1975; Turner and Dimmick 1981; Gehlbach 1994; summarized in Gehlbach 1995, Table 1). I calculated the total number of prey species at each site but tallying invertebrates only at the family level with items identified only to genus or group only included if no other member of that group had been tallied as a species. As differences in sample size prevented direct comparison, I divided all species counts by the square root of the sample size to produce a simple prey diversity index. In addition to overall calculations by human density category and biological period, I also calculated the same percentages (proportion of prey type consumed), diversity index and niche breadth for each breeding attempt; i.e., I did not pool data across years for sites where nesting occurred more than once. These data were analyzed with a Chisquare test (Ritchison and Cavanagh 1992) and multiple discriminant analysis (MDA) for differences between biological periods and between high-density suburban, low-density suburban, and rural sites. I examined box plots and log transformed diversity index and arcsine transformed percentage variables as necessary to reduce heteroscedacity before performing the MDA. 
TABLE 1. Prey of Eastern Screech-Owl from 2004 to 2008: sources of the data.

\begin{tabular}{|c|c|c|c|c|c|c|c|c|}
\hline & Bird & Mammal & Other V. & Invert. & Rural & $\begin{array}{l}\text { Suburb - } \\
\text { low }\end{array}$ & $\begin{array}{l}\text { Suburb - } \\
\text { high }\end{array}$ & TOTAL \\
\hline \multicolumn{9}{|l|}{ Observations } \\
\hline Field obs. & 15 & 24 & 4 & 746 & 97 & 501 & 191 & 789 \\
\hline Video & 62 & 30 & 4 & 129 & 0 & 0 & 225 & 225 \\
\hline $\begin{array}{l}\text { Total obs. } \\
\text { Remains }\end{array}$ & 77 & 54 & 8 & 875 & 97 & 501 & 416 & $1014(44 \%)$ \\
\hline Pellets & 221 & 367 & 0 & 249 & 83 & 586 & 168 & 837 \\
\hline Nests & 46 & 8 & 0 & 418 & 317 & 97 & 58 & 472 \\
\hline Total remains & 267 & 375 & $\mathbf{0}$ & 667 & 400 & 683 & 226 & $1309(56 \%)$ \\
\hline TOTAL & 344 & 429 & 8 & 1542 & 497 & 1184 & 642 & 2323 \\
\hline
\end{tabular}

Other V. refers to amphibians and fish, obs. = observations, Nests refers to the inspection of nest sites after all young had fledged.

\section{Results}

I identified 2323 prey items from March 2004 to February 2008 from four sources: field observations $(n=789)$; video footage $(n=225)$; analysis of pellets $(n=837)$; and inspection of nest boxes $(n=472)$ (Table 1). I found 637 pellets, ranging in size from $8 \times 4 \mathrm{~mm}$ to $51 \times 12 \mathrm{~mm}$ (but sometimes as much as $20 \mathrm{~mm}$ wide in part due to flattening) and averaging $25.4 \times 10.5 \mathrm{~mm}$. The number of prey items from observations and remains were similar, 1014 (44\%) and 1309 (56\%) respectively; however, the ratio of observations to pellets was not constant at all sites and care is needed when drawing conclusions about comparative capture rates (Table 1). Eight mammal prey species were recorded. Meadow Vole (Microtus pennsylvanicus) was by far the most important individual prey species (63\% of mammalian prey and $75 \%$ of mammalian biomass). Including 20 unidentified voles, voles constituted $68 \%$ of all mammal prey and $81 \%$ of the mammalian biomass consumed. Meadow Voles constituted 9\% (rural) - 12\% (low and high-density suburban) of all prey during breeding and $2 \%$ (rural) $20 \%$ (low-density suburban) $-45 \%$ (high-density suburban) in the non-breeding season. House Mouse (Mus musculus) (13\%) and North American Deermouse (Peromyscus maniculatus) (6\%) were also regular prey. Little Brown Bat (Myotis lucifugus) (1\%) and Northern Short-tailed Shrew (Blarina brevicauda) (1\%) were rarely consumed. House Mouse was absent from rural sites and ranged from 3\% (low-density suburban) and $2 \%$ (high-density suburban) during breeding to $6 \%$ (low-density suburban) and 10\% (high-density suburban) in the non-breeding season.

A total of 26 bird species were recorded as prey; however, many bird remains could not be identified to species. Birds consumed were largely passerine $(82 \%)$ and the majority were small species under $40 \mathrm{~g}(55 \%$ $<20 \mathrm{~g}, 34 \% 20-40 \mathrm{~g}, 11 \%>40 \mathrm{~g}$ ), contrary to Gehlbach (1994). The most commonly recorded avian prey species were House Sparrow (Passer domesticus) (13\% of all birds) and Black-capped Chickadee (Poecile atricapillus) (9\%). House Sparrow was much less common in high-density suburban and rural areas $(<1 \%)$ than in low-density suburban sites. Yellow-rumped Warbler (Dendroica coronata) (3\%) was the most commonly captured migrant. The largest avian prey captured were Rock Pigeons (Columba livia) and Blue Jays (Cyanocitta cristata), as well as a single Virginia Rail (Rallus limicola), a species seldom recorded within the city of Winnipeg (personal observations). The only two amphibian prey items confirmed to species were Northern Leopard Frog (Lithobates pipiens) and Wood Frog (Rana sylvatica) and only a single unidentified fish was found.

Fifty-seven percent of invertebrates consumed were detected using observational techniques, compared to $22 \%$ for birds and $13 \%$ for mammals. Invertebrates consumed included insects, earthworms, crustaceans, arachnids, gastropods, and many unidentified items. Most invertebrates consumed were insects, and of these beetles were the most common group (43\% of invertebrates), presumably because their remains are readily found and identified in pellets and nest boxes. The family Scarabidae constituted $83 \%$ of the beetles identified, of which many appeared to be in the genus Phyllophaga. After beetles, the next most important invertebrate prey were both soft-bodied, the earthworm Lumbricus terrestris (5\%) and various caterpillars (4\%). Earthworms were most commonly captured in low-density suburban areas (1\% of all rural prey in the breeding season, $5 \%$ low suburban, $3 \%$ high suburban). The proportion of invertebrate prey captured by three unpaired males ( $\xi \pm$ SE: $27.3 \pm 14.2 \%$ ) was much lower than for breeding pairs $(75.7 \pm 5.6 \%)$. Unpaired males caught mammals $(56 \pm 20.9 \%)$ more frequently than breeding pairs (12.2 $\pm 3.8 \%)$ (MANOVA, Wilk's Lamba $=0.6, F=6.38, \mathrm{df}=2,19$, $P=0.008$ ); however, the data on the diets of unpaired males were collected primarily from pellets found at roost sites and are therefore biased due to a lack of observational information.

Despite being unavailable to the owls in winter, invertebrates constituted by far the largest proportion of total prey captures ( $66 \%$ overall, $71 \%$ in the breed- 
TABLE 2. Prey of Eastern Screech-Owl from 2004 - 2008: prey captures by period.

\begin{tabular}{llllll}
\hline \hline Period & Bird & Mammal & Amphibian and fish & Invertebrate & Total \\
\hline Winter & $22(50 \%)$ & $22(50 \%)$ & 0 & 0 & 44 \\
Pre-egg laying & $68(38 \%)$ & $66(37 \%)$ & 0 & $44(25 \%)$ & 178 \\
Incubating & $82(19 \%)$ & $209(49 \%)$ & $3(1 \%)$ & $131(31 \%)$ & 425 \\
Brooding & $124(17 \%)$ & $110(15 \%)$ & $5(1 \%)$ & $476(67 \%)$ & 715 \\
Post-fledging & $25(5 \%)$ & $18(3 \%)$ & 0 & $491(92 \%)$ & 534 \\
Summer & $23(5 \%)$ & $4(1 \%)$ & 0 & $400(94 \%)$ & 427 \\
Total & $\mathbf{3 4 4}(\mathbf{1 5 \% )}$ & $\mathbf{4 2 9}(\mathbf{1 8 \% )}$ & $\mathbf{8}(<\mathbf{1 \%})$ & $\mathbf{1 5 4 2}(\mathbf{6 6 \% )})$ & $\mathbf{2 3 2 3}$ \\
\hline \hline
\end{tabular}

Percentages indicate the number prey in each period against the total number of prey in that period.

TABLE 3. Prey of Eastern Screech-Owl from 2004 - 2008: biomass consumed by period.

\begin{tabular}{llllll}
\hline \hline Period & Bird & Mammal & Amphibian and fish & Invertebrate & Total \\
\hline Winter & $588 \mathrm{~g}(40 \%)$ & $878 \mathrm{~g}(60 \%)$ & $0 \mathrm{~g}$ & $0 \mathrm{~g}$ & $1466 \mathrm{~g}$ \\
Pre-egg laying & $1710 \mathrm{~g}(39 \%)$ & $2599 \mathrm{~g}(59 \%)$ & $0 \mathrm{~g}$ & $91 \mathrm{~g}(2 \%)$ & $4399 \mathrm{~g}$ \\
Incubating & $2689 \mathrm{~g}(23 \%)$ & $8690 \mathrm{~g}(74 \%)$ & $34 \mathrm{~g}(<1 \%)$ & $284 \mathrm{~g}(2 \%)$ & $11697 \mathrm{~g}$ \\
Brooding & $3419 \mathrm{~g}(37 \%)$ & $4645 \mathrm{~g}(51 \%)$ & $85 \mathrm{~g}(1 \%)$ & $1033 \mathrm{~g}(11 \%)$ & $9182 \mathrm{~g}$ \\
Post-fledging & $627 \mathrm{~g}(26 \%)$ & $719 \mathrm{~g}(30 \%)$ & $0 \mathrm{~g}$ & $803 \mathrm{~g}(44 \%)$ & $2413 \mathrm{~g}$ \\
Summer & $568 \mathrm{~g}(37 \%)$ & $167 \mathrm{~g}(11 \%)$ & $0 \mathrm{~g}$ & $\mathbf{3 2 7 7} \mathbf{g}(\mathbf{1 1 \%})$ & $1537 \mathrm{~g}$ \\
Total & $\mathbf{9 6 0 1 g}(\mathbf{3 1 \%})$ & $\mathbf{1 7 6 9 8 g}(\mathbf{5 8 \%})$ & $\mathbf{1 1 9 g}(<\mathbf{1 \%})$ & $\mathbf{3 0 6 9 5}$ \\
\hline \hline
\end{tabular}

Percentages indicate the total biomass per category in each period against the overall biomass in that period.

ing season, $20 \%$ in the non-breeding season) (Table 2). Mammals are the next highest group (18\% overall, $16 \%$ breeding, $40 \%$ non-breeding) but only slightly higher than birds (15\% overall, $12 \%$ breeding, $40 \%$ non-breeding). Amphibians and fish, which are also unavailable to the owls in winter, were a very small component ( $<1 \%$ overall). The number of birds, mammals, amphibians and fish, and invertebrates consumed (Table 2) varied significantly by biological period $\left(\chi^{2}=854.3\right.$, df $\left.=15, P<0.001\right)$. Mammals were captured more than birds overall; however, birds and mammals were consumed in equal proportions in the non-breeding season (Mammals captured: $16 \%$ breeding, $40 \%$ non-breeding, $50 \%$ winter only; birds captured: $12 \%$ breeding, $40 \%$ non-breeding, $50 \%$ winter only). Despite the high percentages of invertebrates captured, invertebrates constituted only $11 \%$ of the biomass consumed (13\% breeding, $2 \%$ non-breeding) (Table 3). Although their capture rates were only slightly higher, mammals contributed much more to biomass consumed than birds (58\% versus $31 \%$ overall, $57 \%$ versus $29 \%$ breeding, $59 \%$ versus $40 \%$ non-breeding). The ratio of vertebrates to invertebrates did not vary by year $\left(\chi^{2}=0.36\right.$, df $\left.=3, P=0.95\right)$; however, there was annual variation in the type of invertebrates consumed, for example, earthworms were highest in the wettest year $(17 \%$ of invertebrate captures in 2004 when precipitation from March - September totaled $531 \mathrm{~mm}$ down to zero in 2006 when March - September precipitation was only $231 \mathrm{~mm}$ ) (Environment Canada, no date.).

The MDA comparison of prey type by period (not including the unspecified summer period) identified two significant axes, viz. canonical 1: canonical correlation $=0.91$, likelihood ratio $=0.03, F=3.57, \mathrm{df}=$ $48,113.75, P<0.001$ and canonical 2 : canonical correlation $=0.84$, likelihood ratio $=0.17, F=2.21$, $\mathrm{df}=33$, $89.09, p=0.001$ (Table 4 ). The MDA correctly classified $60 \%$ of the pre-breeding period, $91 \%$ of the incubation period, $67 \%$ of the brooding period, $86 \%$ of the post-fledging period, and $100 \%$ of the winter period. The first two canonical axes from the MDA (Figure 1.) show strong separation of the diet in biologically significant periods, primarily by the distribution of the prey classes and diversity. Canonical axis 1 is highly correlated to percent mammals $(0.85$, total canonical structure) and birds (0.78) and negatively correlated to percent invertebrates $(-0.96)$. Within the prey classes, this axis was correlated strongly to rodents (0.54) and negatively to soft-bodied invertebrates $(-0.51)$. Niche breadth $(0.54)$ and prey diversity $(0.47)$ were also important. Canonical axis one therefore represents a gradient of increasing vertebrate and decreasing invertebrate consumption (especially soft-bodied invertebrates) and the winter and pre-breeding periods thus score highest (Figure 1). Canonical axis 2 was strongly correlated with hard-bodied invertebrates (0.6), niche breadth (0.47), non-rodents (0.39), amphibians and fish (0.31), mammals (0.31), and diversity (0.26). It was negatively correlated to birds $(-0.13)$, in particular resident birds (-0.19). Canonical axis 2 is thus a gradient of increasing mammal consumption, including increasing diversity of mammals (addition of non-rodents) and higher niche breadth but slightly lower bird consumption, in particular fewer migratory species. Accordingly the incubation and brooding peri- 
TABLE 4. Total canonical structure from MDA for prey type differences between biologically significant periods and human density categories.

\begin{tabular}{|c|c|c|c|c|}
\hline & \multicolumn{2}{|c|}{ By Period } & \multicolumn{2}{|c|}{ By Human Density Category } \\
\hline & Canonical 1 & $\overline{\text { Canonical } 2}$ & Canonical 1 & Canonical 2 \\
\hline Birds $†$ & 0.34 & 2.24 & 0.25 & 0.6 \\
\hline Resident birds $\dagger$ & -0.36 & -0.32 & 0.11 & -0.15 \\
\hline Migrant birds $\dagger$ & -0.08 & -0.04 & 0.41 & 0.09 \\
\hline Mammals $\dagger$ & -0.47 & 4.07 & 0.5 & -0.05 \\
\hline Rodents $†$ & 0.07 & -0.31 & 0.5 & 0.06 \\
\hline Non-rodents $\dagger$ & 0.54 & 0.18 & 0.14 & 0.38 \\
\hline Amphibian/ fish & 0.26 & 0.90 & 0.23 & -0.2 \\
\hline Invertebrates $\dagger$ & -1.62 & 3.85 & -0.46 & -0.03 \\
\hline Hard bodied $\dagger$ & 0.14 & 0.30 & 0.31 & 0.34 \\
\hline Soft bodied $\dagger$ & 0.24 & 0.53 & -0.12 & 0.23 \\
\hline Diversity $\S$ & -0.68 & -0.41 & 0.3 & 0.58 \\
\hline Niche breadth & -0.06 & -0.38 & 0.18 & 0.5 \\
\hline
\end{tabular}

$\S$ indicated that the variable was log transformed. $\dagger$ indicates the arcsine transformation.

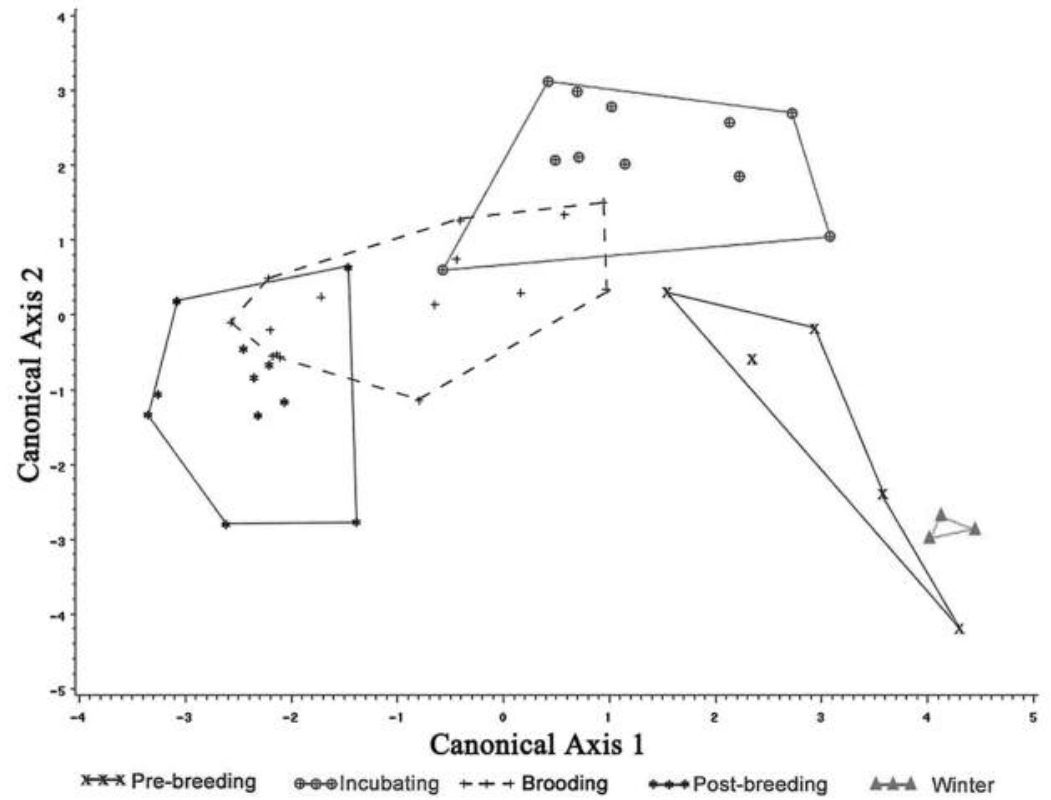

FIGURE 1. Scatter plot of canonical 1 and 2 scores from MDA for prey types differences between biologically significant periods.

ods scored highest on this axis, whereas the winter and pre-breeding periods scored lowest (Figure 1).

The percentages of birds, mammals, amphibians and fish, and invertebrates consumed overall differed between rural, low-density suburban and high-density suburban sites $\left(\chi^{2}=17.2, \mathrm{df}=6, P=0.008\right)$ (Table 5). Owls on rural sites consumed fewer birds than owls in low and high-density suburban sites in both the breeding and non-breeding seasons (9\% fewer than lowdensity suburban owls in the breeding season and $30 \%$ fewer in the non-breeding season). The ratio of resident and locally breeding species to passage migrant and non-breeding visitors was approximately 2:1 on all sites (Table 5). Owls on low-density suburban sites consumed almost double the amount of birds in the non-breeding season as owls in high-density sites and triple that of birds in rural sites. Owls in rural areas consumed fewer mammals in the breeding season than either group of suburban owls. However, owls in high-density suburban areas consumed more mammals in the non-breeding season. Mammalian diversity in the diet was greater on low-density suburban sites, there being no shrews or bats consumed anywhere else. Owls on rural sites consumed $16 \%$ more invertebrates 
TABLE 5. Percentage prey distribution, diversity and niche breadth in breeding ( $\mathrm{Br}$ ) and non-breeding (Non-br) seasons by human density category.

\begin{tabular}{|c|c|c|c|c|c|c|}
\hline & \multicolumn{2}{|c|}{ Rural } & \multicolumn{2}{|c|}{ Suburban - low } & \multicolumn{2}{|c|}{ Suburban - high } \\
\hline & $\mathrm{Br}$ & Non-br & $\mathrm{Br}$ & Non-br & $\mathrm{Br}$ & Non-br \\
\hline Total sample size & 490 & 7 & 998 & 186 & 613 & 29 \\
\hline Birds & 4.3 & 14.3 & 12.9 & 44.1 & 17.0 & 24.1 \\
\hline Resident birds & 66.7 & 100.0 & 63.2 & 70.3 & 65.9 & 83.3 \\
\hline Migrant birds & 33.3 & 0.0 & 36.8 & 29.7 & 34.1 & 16.7 \\
\hline Mammals & 10.6 & 42.9 & 18.0 & 33.9 & 17.8 & 75.9 \\
\hline Rodents & 100.0 & 100.0 & 92.6 & 96.7 & 100.0 & 100.0 \\
\hline Non-rodents & 0.0 & 0.0 & 5.1 & 3.3 & 0.0 & 0.0 \\
\hline Amphibians and fish & 0.4 & 0.0 & 0.3 & 0.0 & 0.7 & 0.0 \\
\hline Invertebrates & 84.7 & 42.9 & 68.7 & 22.0 & 64.6 & 0.0 \\
\hline Hard bodied & 94.9 & 0.0 & 66.1 & 85.0 & 65.5 & 0.0 \\
\hline Soft bodied & 4.8 & 100.0 & 33.3 & 15.0 & 33.1 & 0.0 \\
\hline Average prey sp/site & 14.0 & 4.0 & 15.2 & 10.5 & 11.3 & 7.0 \\
\hline Niche breadth - class & 1.4 & 2.6 & 1.9 & 2.8 & 2.1 & 1.6 \\
\hline Niche breadth - species & 2.2 & 4.5 & 6.1 & 12.4 & 4.9 & 3.8 \\
\hline
\end{tabular}

Percentages of birds, mammals, amphibians and fish, and invertebrates are calculated against the total number of prey items for each of the three human density categories. Other percentages are of against the total number of birds, mammals, or invertebrates that could be identified to species or genus level and were thus classifiable into subgroups.

than low-density suburban owls, $20 \%$ more than highdensity suburban owls in the breeding season, and $21 \%$ and $43 \%$ more respectively in the non-breeding season $\left(\chi^{2}=27.6, \mathrm{df}=2, P<0.001\right)$. Rural owls also consumed a higher proportion of hard-bodied invertebrates and fewer earthworms and caterpillars. Prey species diversity and overall niche breadth was highest at low-density suburban sites. Rural sites had higher diversity in the breeding season than high-density suburbs and vice-versa in the non-breeding season. Niche breadth was higher overall in high-density suburbs compared to rural areas but only marginally. Seasonal differences in niche breadth in these categories reflect smaller sample sizes.

The MDA comparison of prey type among rural, low-density suburban, and high-density suburban sites identified one significant axis and one non-significant axis, viz. canonical 1: canonical correlation $=$ 0.94 , likelihood ratio $=0.05, F=2.58, \mathrm{df}=24,18$, $P=0.02$ and canonical 2: canonical correlation $=$ 0.76 , likelihood ratio $=0.42, F=1.26, \mathrm{df}=11,10, P$ $=0.36$. The MDA correctly classified $100 \%$ of rural sites, $100 \%$ of low-density suburban sites and $100 \%$ of high-density suburban sites. The first canonical axis from the MDA (Table 4, Figure 2.) shows strong separation of the diet between rural, low-density suburban, and high-density suburban sites. Canonical axis 1 is correlated to the percentage of mammals consumed (0.5), in particular rodents (0.5); the percentage of birds consumed (0.25), in particular passage migrants and winter visitors (0.41); and amphibians and fish $(0.23)$. It is also correlated with prey diversity $(0.3)$. This axis is strongly negatively correlated with invertebrate consumption (-0.46). Canonical axis 1 is thus a gradient of decreasing invertebrate consumption and correspondingly higher vertebrate consumption (as per-

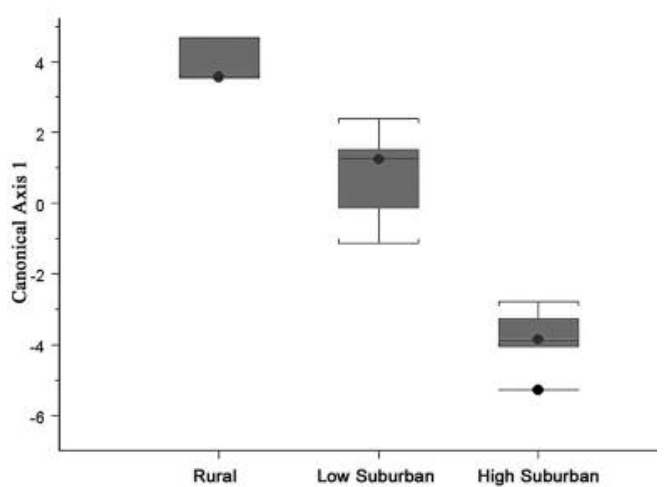

FIGURE 2. Box plot of canonical 1 scores from MDA for prey types differences between rural, low-density suburban and high-density suburban sites.

centages). Since the diversity of invertebrates was only measured to the family level, the higher diversity score on this axis is mostly explained by vertebrates. Rural sites scored highest on this axis; i.e., high invertebrate consumption and low vertebrate consumption, and high-density suburban sites the lowest (Figure 2).

The total niche breadth calculated by species (B) for this study was 6.5; however, the true niche breadth is higher because some diversity is masked by unidentified birds and invertebrates. To facilitate a comparison between studies, I removed invertebrates except crayfish (following Gehlbach 1994) leaving 38 species (some identified only to genus) and a niche breadth of 5.9, much lower than Ohio (69 spp, B = 16.6, VanCamp and Henny 1975) and Texas (72 spp, B = 18.0, Gehlbach 1994). The niche overlap between Manitoba and Ohio (VanCamp and Henny 1975, Table 2) is 
$0.7(70 \%)$, much higher than the overlap between Manitoba and Texas of 0.21 (21\%) (Figure 3). The niche overlap between Ohio and Texas was 0.31 (Gehlbach 1994). A recent study in Québec identified 26 prey items and a niche breadth of only 3.4 (Richards et al. 2006, Table 5); however diet was not the authors' focus and the only method used was periodic inspection of nest boxes. Almost no invertebrates were recorded in Québec due to methodology, so I calculated niche overlap with Manitoba excluding invertebrates as 0.87 , indicating substantial similarities in mammalian and avian prey. Across seven studies where sufficient information on prey composition was provided, there is a non-significant decrease in niche breadth with increasing latitude (linear regression: $t=3.47$, df $=5, P=0.09, R^{2}=0.46$, Figure 3$)$. This trend would likely be significant with greater consistency in methods and sample sizes.

Some species were found as prey in several studies, although their relative importance differed. Peculiar was the absence of Mourning Dove (Zenaida macroura) as a prey item because this species was frequently consumed in other studies at northern locations (VanCamp and Henny 1975; Richards et al. 2006). The Meadow Vole is particularly important in northern diets (68\% of mammals, $13 \%$ overall and $32 \%$ of all winter captures in Manitoba; $75 \%$ of mammals and 52\% overall in Québec; and 37\% of mammals, 13\% overall and $23 \%$ of all captures in the non-breeding season in Ohio). The degree of specialization in Manitoba is comparatively high for a generalist predator, with the three most frequently consumed mammals (Meadow Vole, House Mouse, Deermouse) comprising at least $86 \%$ of mammalian prey (the true percentage may be higher because some prey were not identified to species and if these are excluded is 97\%), and the top three birds (House Sparrow, Black-capped Chickadee, and either Cedar Waxwing or Yellow-rumped Warbler) $23 \%$ of avian prey or $48 \%$ of avian prey identified to species. These percentages are higher than Ohio (top three mammals $85 \%$, top 3 birds $32 \%$ ) and Texas $(76 \%, 39 \%)$.

\section{Discussion}

The high percentage of invertebrates in the diet of the Eastern Screech-Owl and the fact that $57 \%$ of invertebrates were detected using observational techniques demonstrate the need for observation in assessing prey ratios of generalist raptors. The high consumption rate of invertebrates I recorded in the breeding season has only been matched by studies examining stomach contents (Duly 1979, Hanebrink et al. 1979; Brown 1989). Biases in pellet data have been demonstrated in other owls (Plumpton and Lutz 1993, YomTov and Wool 1997; York et al. 2002). Nonetheless, soft-bodied invertebrates, such as moths, worms and caterpillars, recorded almost only by observation, may be under-reported even in this study with multiple

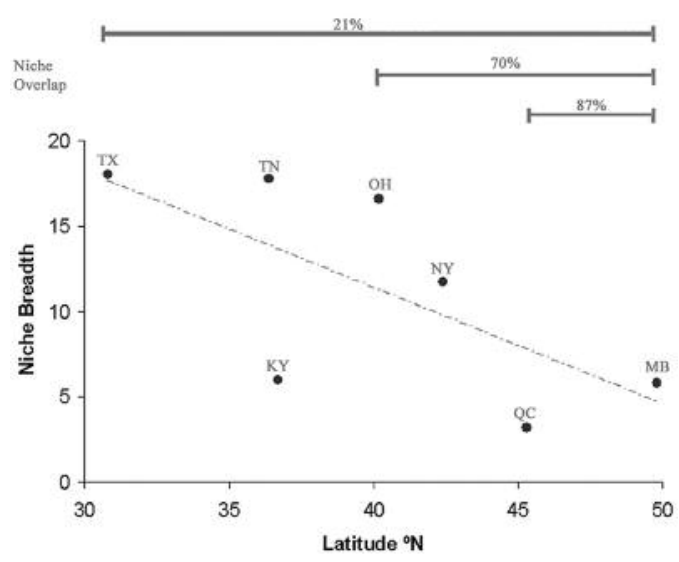

FIGURE 3. Niche breadth (vertebrates and crayfish only) versus latitude from seven studies with niche overlap between Manitoba and Québec, Ohio, and Texas. Data from Manitoba (this study), Québec (Richards et al. 2006), New York (Allen 1924), Ohio (VanCamp and Henny 1975), Kentucky (Ritchison and Cavanagh 1992), Tennessee (Duly 1979), and Texas (Gehlbach 1994).

methods. Invertebrates are by far the most common prey during breeding, despite their relatively small contribution to biomass consumed, whereas birds and mammals become more common in the non-breeding season. This pattern is also found in southern parts of the range (Gehlbach 1994, 1995). The Eastern ScreechOwl has a higher hunting success rate for invertebrates (Abbruzzese and Ritchison 1997) and invertebrates are important for the provisioning of broods, even though they contribute comparatively little biomass, as they can be captured close to the nest and delivered frequently, as often as every 45 seconds in some cases (personal observation). Unpaired males apparently capture larger prey items more regularly and rely less on invertebrate prey than breeding pairs, although limited observational data for unpaired males means this result must be interpreted with care. Variation in the type of invertebrates consumed by year, for example, the ratio of earthworms to beetles, is likely due to accessibility at the surface related to factors including humidity, soil moisture and annual variation in precipitation (Gehlbach 1994).

Screech-owls caught crayfish $(0.5 \%$ of prey captures) and frogs in shallow water; however, fish constituted a smaller proportion of the diet in the study area than elsewhere, with only a single unidentified fish found in this sample, constituting $0.05 \%$ of total prey capture in Manitoba versus $1.3 \%$ of prey capture in Kentucky (Ritchison and Cavanagh 1992), 2.1\% in Texas (Gehlbach 1994), and 3.5\% in Ohio (Van Camp and Henny 1975). As $88 \%$ of nests were within $500 \mathrm{~m}$ of a river of creek (Artuso 2009), it remains unclear why this is the case. 
Niche breadth calculations suggest very different diets in the northern and southern portions of the range of Eastern Screech-Owl, with narrower niches and greater specialization in the north. This northward gradient of specialization is also found in other owls, for example, Boreal Owls in Finland (Korpimäki 1986), whose total niche breadth in western Finland at $63^{\circ} \mathrm{N}$ is only 4.4 (from 40 species of avian and mammalian prey) and whose 3 most frequently consumed mammal species comprise $80 \%$ and the top three bird species $59 \%$ (Korpimäki 1988, calculated by Gehlbach 1994). The Long-eared Owl (Asio otus), often described as a diet specialist, also has a more diverse diet in southern locations (Bertolino et al. 2001). In terms of niche breadth and diet specialization, Manitoban Eastern Screech-Owls, with their high consumption of meadow voles and a few common bird species, are more similar to Finnish Boreal Owls than their Texan conspecifics. The Meadow Vole appears to be particularly important in this northern area. Meadow Voles were more commonly captured in suburban areas (9.5\% of all captured prey in rural areas, $13.2 \%$ in low density suburbs and $13.9 \%$ in high-density suburbs). The trend of decreasing niche breadth with increasing latitude (Figure 3), suggests that this pattern of specialization is driven by the lower diversity of prey types available at northern latitudes. Nonetheless, caution is required in interpreting these results because of differences in methodology between different studies, in particular concerning calculating the consumption rate of invertebrate prey.

Eastern Screech-Owls shift their diet with seasonal availability. Invertebrates consumption increases steadily from pre-laying period to the post-fledging period. Conversely, mammals steadily decline in importance through the breeding season. Although mammals, in particular rodents, were captured more than birds and contributed more to the biomass overall, birds became increasingly important in late fall and winter. Mazur (1992) also reported birds and mammals in equal proportions in the late fall. Birds were also consumed in much higher percentages during the non-breeding season than the breeding season in Texas (Gehlbach 1994) but were only slightly higher in Tennessee (Turner and Dimmick 1981) and Kentucky (Ritchison and Cavanagh 1992) and decreased sharply in Ohio (VanCamp and Henny 1975) and Michigan (Craighead and Craighead 1956). Based on the latter two studies and Allen (1924), Ritchison and Cavanagh (1992) concluded that birds were consumed more frequently in the breeding season at northern locations due to an influx of migrants. This is not supported by this study; however, there is support for VanCamp and Henny's (1975) suggestion that avian prey increases with the arrival of spring migrants, viz. birds were taken less than mammals in the incubation period (19\% versus $49 \%$ ) but became dominant over mammals in the brooding period (17\% versus $15 \%)$ when the peak arrival of Neotropical migrants occurs, and remained slightly higher in the post-fledging period (5\% versus $3 \%$ ). Among avian prey, the percentage of migrants increased in the breeding season and passage migrants had higher Jacob's selectivity indices than resident and locally breeding species (Artuso 2009). The greater importance of avian prey in the winter in Manitoba may be due to accessibility with increasing snow cover. Screech-owls have symmetrical ears and use vision in hunting and are less adapted to the snow-plunging technique of boreal forest species such as the similar-sized Boreal Owl (Aegolius funereus) with asymmetrical ears (Gehlbach 1995). Instead screech-owls in Manitoba hunt mammals in winter at the base of large coniferous trees where snow cover is reduced or when they surface, for example, near bird feeders with fallen seed or when traveling between subnivean tunnels, crossing areas such as driveways where snow has been cleared. House Sparrows and other shrub roosting birds are often hunted by flushing them from roosts.

Screech-owls consumed more invertebrates in rural areas than suburbs, as in Texas during the breeding season (Gehlbach 1994). On the contrary, Burrowing Owls (Athene cunicularia) consume more aerial insects at urban sites than rural sites in Florida (Chipman et al. 2008). Earthworms were most frequently captured in low density-suburbs, presumably because the only species recorded, Lumbricus terrestris, is associated with human activity (Reynolds 2000). In addition, the watering of lawns at night with sprinkler systems may provide greater access to earthworms in suburbs. Consumption of invertebrates began as much as two weeks earlier in suburbs with the first invertebrate prey being recorded on 30 March as opposed to 16 April in rural areas (earliest dates all occurred in 2007), although the smaller sample size in rural areas meant a reduced likelihood of detecting early invertebrate captures there (Table 1). The percentage of invertebrates captured in March and April against total invertebrate capture was $1 \%$ in rural areas, $10 \%$ in lowdensity suburban and $4 \%$ in high-density suburban areas. Although the earlier availability of invertebrate prey is unlikely to be the sole factor permitting earlier nesting in the suburbs, there are additional dietary benefits to early nesting in that recently fledged young who leave the nest on average 5 days earlier in suburban areas than rural areas (Artuso 2009), would have increased availability of avian passage migrants. The earlier availability of invertebrate prey in suburban areas may be related to factors including snow clearance, fertilized gardens, or the urban heat island, which also increases invertebrate diversity in cold climates (Deichsel 2006).

The higher diversity of prey in the non-breeding season in suburbs may relate to the presence of bird species that, despite being uncommon in urban areas in summer, linger or overwinter in the city due in part 
to the urban heat island, regularly replenished anthropogenic food sources, and possibly also due to the protective benefits of planted conifers (Taylor and Koes 1995). Such birds may also be concentrated in small areas with reliable food sources, increasing their accessibility to owls. Species such as Dark-eyed Junco (Junco hyemalis) and White-throated Sparrow (Zonatrichia albicollis), as well as several other Emberizidae and Fringillidae species that are scarce in winter are most likely to occur around feeders and often in suburban and urban areas (Taylor and Koes 1995). Nonetheless, contrary to the generalized remarks of Gehlbach (1995), high-density suburban owls in Winnipeg consumed by far the greatest percentage of mammals in the non-breeding season (76\%), and despite having the highest niche breadth by class in the breeding season, had the lowest niche breadth by class in the nonbreeding season because of the dominance of rodents in the diet and the absence of invertebrates (niche breadth is highest when all prey classes are in equal proportions). The fact that niche breadths by class are higher in the non-breeding than breeding season in both rural and low-density suburban areas may relate to the seasonal shifts in diet which render the prey classes less evenly distributed, in particular that invertebrates are nearly 4 times higher than the next nearest class (mammals) in low-density suburban areas and nearly eight times higher in rural areas in the breeding season.

Several prey species were less frequently captured in rural areas. House Sparrow, the only avian species to compose $>10 \%$ of birds captured, was most frequently captured in low-density suburbs. This species roosts in dense shrubbery, often close to buildings or near feeders or grain sources (Lowther and Cink 2006), and suburbs offer concentrations of them. Tawny Owls (Strix aluco) take advantage of easy access to avian prey at urban roost sites and increase the proportion of birds in their diet in urban areas (Galeotti 1991). The House Mouse was absent from rural diets and the Meadow Vole was most common in suburbs. Those species were the two most significant individual prey items in terms of biomass consumed and were particularly important in the non-breeding season. If these capture rates are reflective of either availability or access then their apparent increased abundance in suburbs would convey an advantage. As the House Mouse in North America is the commensal form that lives mostly in buildings (Banfield 1974), increased availability in suburbs is not surprising. Meadow Voles may be more common in suburban riparian parks than in riparian forest (Mahan and O'Connell 2005) and their density can increase with cottage development (Racey and Euler 1982). With their small home ranges, rodents can thrive in disturbed suburban habitats (Dickman and Doncaster 1987, Nilon and VanDruff 1987); however, rodent diversity declines with increasing amount of impervious surface and bare ground (VanDruff and Rowse 1986). Like Meadow Voles, some other small mammal species such as the Northern Shorttailed Shrew (Blarina brevicauda) are most likely to occur at intermediate disturbance levels (Racey and Euler 1982) and in this study were only found at suburban sites. Small mammal abundance is often higher in small urban patches (Ekernas and Mertes 2006), a phenomenon that may be related to limited dispersal (Barko et al. 2003). This suggests that low-density suburbs may offer the most diversity and abundance of prey species (Blair 1996) and the wider niche breadth and prey diversity of suburban screech-owls therefore reflects availability. Likewise, Burrowing Owls in Florida enjoyed higher prey densities close to buildings (Millsap and Bear 2000). Access to rodent prey in suburbs may also be higher due to nocturnal feeding on fallen seed under bird feeders, snow clearance, and the greater number of coniferous trees under which little snow accumulates (Artuso 2009).

The dietary regime of the Eastern Screech-Owl at the northern periphery of its range is similar in overall composition to the diets of southerly populations. Nonetheless, niche breadth and prey diversity decrease northward corresponding to availability and seasonal shifts in invertebrate versus vertebrate consumption appear more marked. Suburban areas offered a more diverse diet than rural areas, especially in biologically stressful periods; however, niche breadth and diversity peaked in low-density suburbs and declined as human density increased above $30 \mathrm{p} / \mathrm{ha}$.

\section{Acknowledgments}

Funding was provided by The Special Conservation Fund of Manitoba Conservation, Manitoba Hydro, The Winnipeg Foundation, the Great Gray Owl Fund administered by R. W. Nero, and a donation by Pat Cooper. I thank Robert Roughley, Terry Galloway and Richard Westwood for their assistance in identifying invertebrate prey. I thank Richard K. Baydack, Brigitte De March, James R. Duncan, Frederick R. Gehlbach, Nicola Koper, Erkki Korpimäki, Peter Taylor, and Merlin W. Shoesmith for their thoughtful comments which improved this manuscript.

\section{Literature Cited}

Abbruzzese, C. M., and G. Ritchison. 1997. The hunting behavior of Eastern Screech-owls (Otus asio). Pages 2132 in Biology and conservation of owls of the Northern Hemisphere. Edited by J. R. Duncan, D. H. Johnson and T. H. Nicholls. North Central Research Station, U.S. Department of Agriculture, St. Paul, Minnesota, U.S.A.

Allen, A. A. 1924. A contribution to the life history and economic status of the screech owl (Otus asio). Auk 41: 1-17.

Artuso C. 2009. Life on the Edge: The Eastern Screech-Owl in Winnipeg. Ph.D. dissertation, University of Manitoba, Winnipeg.

Banfield, A. W. F. 1974. The mammals of Canada. University of Toronto Press, Toronto, Ontario, Canada.

Barko, V. A., G. A. Feldhamer, M. C. Nicholson, and D. K. Davie. 2003. Urban habitat: A determinant of white-foot- 
ed mouse (Peromyscus leucopus) abundance in southern Illinois. Southeastern Naturalist 2: 369-376.

Battin, J. 2004. When good animals love bad habitats: Ecological traps and the conservation of animal populations. Conservation Biology 18: 1482-1491.

Bertolino, S., E. Ghiberti, and A. Perrone. 2001. Feeding ecology of the long-eared owl (Asio otus) in northern Italy: is it a dietary specialist? Canadian Journal of Zoology 79: 2192-2198.

Blair, R. B. 1996. Land use and avian species diversity along an urban gradient. Ecological Applications 6: 506-519.

Botelho, E. S., and P. C. Arrowood. 1996. Nesting success of western Burrowing Owls in natural and human-altered environments. Pages 61-68 in Raptors in human landscapes: adaptations to built and cultivated environments. Edited by D. M. Bird, D. E. Varland and J. J. Negro. Academic Press, London, U.K.

Brown, R. K. 1989. Food habits of Kentucky owls. Kentucky Warbler 65: 38-48.

Cahn, A. R., and J. T. Kemp. 1930. On the food of certain owls in east-central Illinois. Auk 47: 323-328.

Chipman, E. D., N. E. McIntyre, R. E. Strauss, M. C. Wallace, J. D. Ray, and C. W. Boal. 2008. Effects of human land use on western Burrowing Owl foraging and activity budgets. Journal of Raptor Research 42: 87-98.

Craighead J. J., and F. C. Craighead. 1956. Hawks, owls, and wildlife. Stackpole Company, Harrisburg, Pennsylvania, USA.

Deichsel, R. 2006. Species change in an urban settingground and rove beetles (Coleoptera: Carabidae and Staphylinidae) in Berlin. Urban Ecosystems 9: 161-178.

Dickman, C.R., and C. P. Doncaster. 1987. The ecology of small mammals in urban habitats. Volume 1. Populations in a patchy environment. Journal of Animal Ecology 56: 629-640.

Diermen, J. 1996. Sparrowhawk (Accipiter nisus) breeding in village, rural landscape and forest. De Levende Matuur 97: 43-51.

Duly, L. J. 1979. Life history aspects of the screech owl (Otus asio) in Tennessee. Thesis, University of Tennessee, Knoxville, Tennessee, U.S.A.

Ekernas, L. S., and K. J. Mertes. 2006. The influence of urbanization, patch size, and habitat type on small mammal communities in the New York Metropolitan Region. WildMetro, New York, New York, USA.

Elbroch, M., and E. Marks. 2001. Bird tracks and sign. Stackpole, Mechanicsburg, Pennsylvania, USA. Environment Canada. Weather Pages. Retrieved December 2008 from: http://weatheroffice.ec.gc.ca

Errington, P. L. 1932. Food habits in southern Wisconsin raptors. Part I. Owls. Condor 34: 176-186.

Faeth, S. H., P. S. Warren, E. Shochat, and W. Marussich. 2005. Trophic dynamics in urban communities. BioScience 55: 399-407.

Fisher, A. K. 1893. Hawks and owls of the U.S. U.S. Department of Agriculture, Division of Ornithology and Mammalogy Bulletin 3: 163-174.

Galeotti, P. 1991. Feeding ecology of the tawny owls (Strix aluco) in urban habitats (northern Italy). Bolletino di Zoologia 58: 143-150.

Gehlbach, F. R. 1994. The Eastern Screech Owl: Life history, ecology, and behavior in the suburbs and countryside. Texas A\&M University Press, College Station, Texas, U.S.A.
Gehlbach, F. R. 1995. Eastern Screech-Owl. Account 165 in The Birds of North America. Edited by A. Poole and F. Gill. American Ornithological Union and the Academy of Natural Sciences of Philadelphia, Philadelphia, Pennsylvania, U.S.A.

Hanebrink, E. L., A. F. Posey, and K. Sutton. 1979. A note on the food habits of selected raptors from northeastern Arkansas. Arkansas Academy of Science Proceedings 33: 79-80.

Jensen, K. H., S. Rauch, G. M. Morrison, and P. Lindberg. 2002. Platinum group elements in the feathers of raptors and their prey. Archives of Environmental Contamination and Toxicology 42: 338-347.

Kays, R. W., and D. E. Wilson. 2002. Mammals of North America. Princeton Field Guides. Princeton University Press, New Jersey, USA.

Korpimäki, E. 1986. Gradients in population fluctuation of Tengmalm's owl Aegolius funereus in Europe. Oecologia 69: 195-201.

Korpimäki, E. 1988. Diet of breeding Tengmalm's owl Aegolius funereus: long-term changes and year to year variation under cyclic food conditions. Ornis Fennica 65: 21-30.

Korschgen, L. J., and H. B. Stuart. 1972. Twenty years of avian predator-small mammal relationships in Missouri. Journal of Wildlife Management 36: 269-282.

Kostelecka-Myrcha, A., J. Zukowski, and E. Oksiejczuk. 1997. Changes in the red blood indices during nestling development of the Tree Sparrow Passer montanus in an urban environment. Ibis 139: 92-96.

Lowther, P. E., and C. L. Cink. 2006. House Sparrow (Passer domesticus), The Birds of North America Online. Edited by A. Poole. Ithaca: Cornell Lab of Ornithology; Retrieved September 2008 from the Birds of North America Online: http://bna.birds.cornell.edu/bna/species/012doi: 10.2173/bna.12

Mahan, C. G., and T. J. O'Connell. 2005. Small mammal use of suburban and urban parks in central Pennsylvania. Northeastern Naturalist 12: 307-314.

Mazur, K. M. 1992. Fall Food of the Eastern Screech-Owl in Manitoba. Blue Jay 50: 33-35.

Millsap, B. A., and C. Bear. 2000. Density and Reproduction of Burrowing Owls along an Urban Development Gradient. Journal of Wildlife Management 64: 33-41.

Nilon, C. H., and L. W. VanDruff. 1987. Analysis of small mammal community data and applications to management of urban greenspaces. Pages 53-59 in Integrating Man and Nature in the Metropolitan Environment. Edited by L. W. Adams and D. L. Leedy. National Institute Urban Wildlife, Columbia, Maryland, U.S.A.

Plumpton, D. L., and R. S. Lutz. 1993. Prey selection and food habits of Burrowing Owls in Colorado. Great Basin Naturalist 53: 299-304.

Racey, G. D., and D. L. Euler. 1982. Small mammal and habitat response to shoreline cottage development in central Ontario. Canadian Journal of Zoology 60: 865-880.

Remes, V. 2000. How can maladaptive habitat choice generate source-sink population dynamics? Oikos 91: 579-582.

Reynolds, J. W. 2000. A contribution to our knowledge of the earthworm fauna of Manitoba, Canada (Oligochaeta, Lumbricidae), Megadrilogica 8: 9-12.

Richards, N. L., P. Mineau, D. M. Bird, P. Wery, J. Larivée, and J. Duffe. 2006. First observations of an Eastern Screech-Owl, Megascops asio, population in an apple- 
producing region of southern Quebec. Canadian FieldNaturalist 120: 289-293.

Ritchison G., and P. M. Cavanagh. 1992. Prey use by Eastern Screech Owls: seasonal variation in central Kentucky and a review of previous studies. Journal of Raptor Research. 26: 66-73.

Sibley, D. A. 2000. National Audubon Society - The Sibley Guide to Birds. Knopf, New York, U.S.A.

Stewart, P. A. 1969. Prey in two screech owl nests. Auk 86: 141.

Taylor, P., and R. Koes. 1995. Rare and marginal winter passerine birds in Manitoba. Blue Jay 53: 148-158.

Turner, L. J., and R. W. Dimmick. 1981. Seasonal prey capture by the screech owl in Tennessee. Journal of Tennessee Academy of Science 56: 56-59.

U.S. National Fish and Wildlife Forensics Laboratory. Feather Atlas Website. Retrieved September 2004 December 2008 from http://www.lab.fws.gov/featheratlas.

VanCamp, L. F., and C. J. Henny. 1975. The Screech Owl: Its Life History and Population Ecology in Northern Ohio. North American Fauna: 71. Unites States Department of the Interior Fish and Wildlife Service.
VanDruff, L. W., and R. N. Rowse. 1986. Habitat association of mammals in Syracuse, New York. Urban Ecology 9: 413-434.

Wageningen University Experimental Zoology Group. Skull site. Retrieved September 2004 - December 2008 from: http://www.skullsite.com/index.htm.

Wilson, K. A. 1938. Owl studies at Ann Arbor, Michigan. Auk 55: 187-197.

Wolf, B. O., and C. M. del Rio. 2000. Use of saguaro fruit by white-winged doves: isotopic evidence of a tight ecological association. Oecologia 124: 536-543.

Yom-Tov, Y., and D. Wool. 1997. Do the contents of Barn Owl pellets accurately represent the proportion of prey species in the field? Condor 99: 972-976.

York, M. M., D. K. Rosenberg, and K. K. Sturm. 2002. Diet and food-niche breadth of Burrowing Owls (Athene cunicularia) in the Imperial Valley, California. Western North American Naturalist 62: 280-287.

Received 31 October 2009

Accepted 23 September 2010

APPENDIX: Prey by species of Eastern Screech-Owl from March 2004 - February 2008.

\begin{tabular}{|c|c|c|}
\hline Prey Item & Total Captured & Biomass \\
\hline BIRDS & $\mathrm{n}=344$ & $9601 \mathrm{~g}$ \\
\hline Passerines & $282(82 \%)$ & $5984 g(62 \%)$ \\
\hline Non-passerines & $11(3 \%)$ & $1444 \mathrm{~g}(15 \%)$ \\
\hline Unidentified bird & $51(15 \%)$ & $2173 g(23 \%)$ \\
\hline Unidentified small passerine & $90(26 \%)$ & $1782 \mathrm{~g}(19 \%)$ \\
\hline House Sparrow & $43(13 \%)$ & $1204 \mathrm{~g}(13 \%)$ \\
\hline Unidentified sparrow or finch & $33(10 \%)$ & $662 \mathrm{~g}(7 \%)$ \\
\hline Black-capped Chickadee & $30(9 \%)$ & $330 \mathrm{~g}(3 \%)$ \\
\hline Unidentified warbler & $19(6 \%)$ & $190 \mathrm{~g}(2 \%)$ \\
\hline Cedar Waxwing & $9(3 \%)$ & $288 \mathrm{~g}(3 \%)$ \\
\hline Yellow-rumped Warbler & $9(3 \%)$ & $111 \mathrm{~g}(1 \%)$ \\
\hline American Redstart & $7(2 \%)$ & $58 \mathrm{~g}(1 \%)$ \\
\hline Yellow Warbler & $6(2 \%)$ & $57 \mathrm{~g}(1 \%)$ \\
\hline House Finch and Carpodacus sp & $6(2 \%)$ & $128 \mathrm{~g}(1 \%)$ \\
\hline White-breasted Nuthatch & $4(1 \%)$ & $84 \mathrm{~g}(1 \%)$ \\
\hline Rock Pigeon & $4(1 \%)$ & $1080 \mathrm{~g}(11 \%)$ \\
\hline American Robin & $3(1 \%)$ & $231 \mathrm{~g}(2 \%)$ \\
\hline Catharus sp & $3(1 \%)$ & $93 \mathrm{~g}(1 \%)$ \\
\hline Hairy Woodpecker & $3(1 \%)$ & $198 \mathrm{~g}(2 \%)$ \\
\hline Downy Woodpecker & $3(1 \%)$ & $81 \mathrm{~g}(1 \%)$ \\
\hline Tennessee Warbler & $3(1 \%)$ & $30 \mathrm{~g}(0.3 \%)$ \\
\hline Northern Shrike & $2(1 \%)$ & $130 \mathrm{~g}(1 \%)$ \\
\hline Blue Jay & $2(1 \%)$ & $170 \mathrm{~g}(2 \%)$ \\
\hline American Goldfinch & $2(1 \%)$ & $26 \mathrm{~g}(0.3 \%)$ \\
\hline European Starling & $2(1 \%)$ & $164 \mathrm{~g}(2 \%)$ \\
\hline House Wren & $2(1 \%)$ & $22 \mathrm{~g}(0.2 \%)$ \\
\hline Dark-eyed Junco & $2(1 \%)$ & $38 \mathrm{~g}(0.4 \%)$ \\
\hline Virginia Rail & $1(0.3 \%)$ & $85 \mathrm{~g}(1 \%)$ \\
\hline White-throated Sparrow & $1(0.3 \%)$ & $26 \mathrm{~g}(0.3 \%)$ \\
\hline Baltimore Oriole & $1(0.3 \%)$ & $33 \mathrm{~g}(0.3 \%)$ \\
\hline Pine Grosbeak & $1(0.3 \%)$ & $56 \mathrm{~g}(1 \%)$ \\
\hline Rose-breasted Grosbeak & $1(0.3 \%)$ & $45 \mathrm{~g}(0.5 \%)$ \\
\hline Regulus sp & $1(0.3 \%)$ & $6 \mathrm{~g}(0.1 \%)$ \\
\hline
\end{tabular}


APPENDIX: (continued)

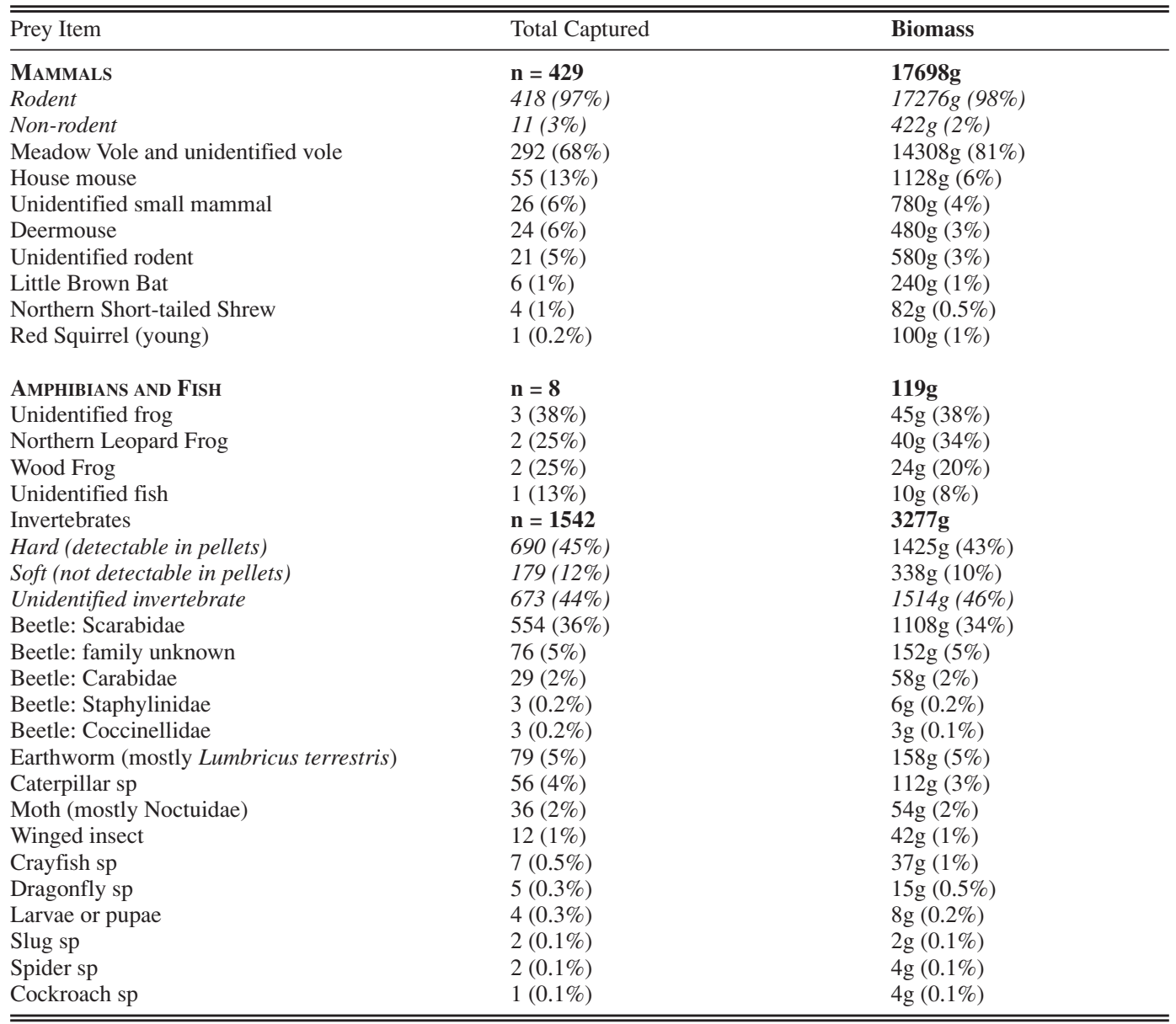

Twenty "Microtus sp" are all most likely to be Meadow Voles hence combined. Beetle identifications are imperfect and the number of Scarabidae may be inflated due to other families with similar head or leg shapes. Most of the unidentified invertebrates were observed and were most likely small beetles or other very small prey. The most common Scarabidae prey are in the genus Phyllophaga, the most common Carabidae prey are in the genus Calosoma. 